Article

\title{
The VIS/NIR Land and Snow BRDF Atlas for RTTOV: Comparison between MODIS MCD43C1 C5 and C6
}

\author{
Jérôme Vidot ${ }^{1, *}$, Pascal Brunel ${ }^{1}$, Marie Dumont ${ }^{2}$, Carlo Carmagnola ${ }^{2}$ and James Hocking ${ }^{3}$ \\ 1 Météo-France, CMS, F-22300 Lannion, France; pascal.brunel@meteo.fr \\ 2 Météo-France-CNRS, CNRM, UMR 3589, CEN, F-38400 Saint Martin d'Hères, France; \\ marie.dumont@meteo.fr (M.D.); carlo.carmagnola@meteo.fr (C.C.) \\ 3 MetOffice, Exeter EX1 3PB, UK; james.hocking@metoffice.gov.uk \\ * Correspondence: jerome.vidot@meteo.fr; Tel.: +33-2-96-05-67-66
}

Received: 27 November 2017; Accepted: 21 December 2017; Published: 23 December 2017

\begin{abstract}
A monthly mean land and snow Bidirectional Reflectance Distribution Function (BRDF) atlas for visible and near infrared parts of the spectrum has been developed for Radiative Transfer for Television Infrared Observation Satellite (TIROS) Operational Vertical sounder (TOVS) (RTTOV). The atlas follows the methodology of the RTTOV University of Wisconsin infrared land surface emissivity (UWIREMIS) atlas, i.e., it combines satellite retrievals and a principal component analysis on a dataset of hyper-spectral surface hemispherical reflectance or albedo. The current version of the BRDF atlas is based on the Collection 5 of the Moderate Resolution Imaging (MODIS) MCD43C1 Climate Modeling Grid BRDF kernel-driven model parameters product. The MCD43C1 product combines both Terra and Aqua satellites over a 16-day period of acquisition and is provided globally at $0.05^{\circ}$ of spatial resolution. We have improved the RTTOV land surface BRDF atlas by using the last Collection 6 of MODIS product MCD43C1. We firstly found that the MODIS C6 product improved the quality index of the BRDF model as compared with that of C5. When compared with clear-sky top of atmosphere (TOA) reflectance of Spinning Enhanced Visible and InfraRed Imagers (SEVIRI) solar channels over snow-free land surfaces, we showed that the reflectances are simulated with an absolute accuracy of 3\% to 5\% (i.e., $0.03-0.05$ in reflectance units) when either the satellite zenith angle or the solar zenith angle is below $70^{\circ}$, regardless of the MODIS collection. For snow-covered surfaces, we showed that the comparison with in situ snow spectral albedo is improved with C6 with an underestimation of 0.05 in the near infrared.
\end{abstract}

Keywords: BRDF; RTTOV; MODIS; MCD43C1

\section{Introduction}

The radiative transfer model RTTOV (Radiative Transfer for Television Infrared Observation Satellite (TIROS) Operational Vertical sounder (TOVS) [1,2]) is the fast radiative transfer model (RTM) developed for the assimilation of satellite top of atmosphere (TOA) radiances in many Numerical Weather Prediction (NWP) models. RTTOV is improved and maintained in the frame of the NWP-SAF (Satellite Application Facility) project from the European Organization for the Exploitation of Meteorological Satellites (EUMETSAT). Currently, only TOA radiances in the infrared and the microwave parts of the spectrum are assimilated in NWP models from various polar orbiting and geostationary satellites [3,4]. In version 11 [5], we extended the capability of the RTTOV model to simulate TOA radiances or reflectances for visible to near infrared (VIS/NIR) channels such as the ones of the Moderate Resolution Imaging Spectroradiometer (MODIS) onboard Aqua and Terra, the Visible Infrared Imaging Radiometer Suite (VIIRS) onboard the Suomi-National Polar-orbiting (NPP) and the Joint Polar Satellite System (JPSS) satellites, and all Spinning Enhanced Visible and InfraRed Imagers (SEVIRIs) onboard the series of Meteosat Second Generation (MSG) satellites. If VIS/NIR 
TOA radiances are not currently assimilated in NWP models, many applications can benefit from such capabilities. A very promising application of fast VIS/NIR RTM simulations is already developed for weather forecasters. Forecasters are experts at using and interpreting satellite imagery. Having a way of directly comparing cloud and moisture from the model with observations is a valuable tool for verifying the NWP model in near real time. Simulations of VIS/NIR channels offer new insight for cases where thermal infrared or microwave parts of the spectrum are limited, such as for low clouds, fog, or aerosols.

In order to simulate VIS/NIR satellite observations at all locations, we developed a dedicated land surface Bidirectional Reflectance Distribution Function (BRDF) model for RTTOV in order to provide the surface reflectance in both solar and viewing directions [6]. The land surface BRDF model of RTTOV was inspired from the work of Seemann et al. [7] and is similar to the University of Wisconsin infrared land surface emissivity UWIREMIS model [8] implemented in RTTOV. It combines MODIS land surface properties retrievals in the VIS/NIR with a principal component analysis (PCA) over many vegetation and soil reflectances spectra in order to provide a full spectral, temporal, and spatial description of surface reflectance. The model is currently working from 0.4 to $2.5 \mu \mathrm{m}$ with a spectral resolution of $0.1 \mathrm{~nm}$ and provides a global monthly mean land surface BRDF atlas at a spatial resolution of $0.1^{\circ}$ for the year 2007. The model also provides a quality index and surface types (land or snow) of the BRDF based on the MODIS flags. The MODIS land surface properties retrieval comes from the operational and global MODIS 16-days BRDF kernel-driven product MCD43C1 Collection 5 (C5). In Vidot and Borbás [6], the comparison of the RTTOV BRDF atlas against the SEVIRI surface black-sky albedo products EUMETSAT Land Satellite Application Facility on Land Surface Analysis (Land-SAF) showed a good spatial and temporal consistency of the RTTOV BRDF atlas when applied on the three SEVIRI VIS/NIR channels. It was found that the RTTOV narrowband black-sky albedo was retrieved with an absolute accuracy of \pm 0.01 at $0.6 \mu \mathrm{m}$ (channel 1) and $1.6 \mu \mathrm{m}$ (channel 2). It was also found that the RTTOV narrowband black-sky albedo at $0.8 \mu \mathrm{m}$ (channel 3) was overestimated between 0.01 and 0.03 . It was also found over a period of 9 months that the temporal variation of the RTTOV broadband black-sky albedo is consistent with the EUMETSAT Land-SAF SEVIRI products but overestimated by somewhere between 0.01 and 0.02 when considering the best quality index of the RTTOV BRDF atlas. Finally, less agreement is seen in two particular cases: (i) for extreme geometrical conditions when the satellite zenith angle (SZA) $>65^{\circ}$ and (ii) for lower quality indices of the RTTOV BRDF atlas. A similar methodology has been used by Zoogman et al. [9] to extend the hyperspectral BRDF model in the ultraviolet (UV). This model was applied to multispectral UV + VIS ozone retrieval on the Global Ozone Monitoring Experiment-2 (GOME-2) instrument with significant improvement in fitting residuals over vegetated scenes.

In this work, we present an improvement of the RTTOV land and snow-covered surface BRDF model by using the last collection 6 (C6) of the MODIS land product. The first part of the paper describes the methodology of the BRDF model and provides the main differences between the two MODIS MCD43C1 collections. The second part is devoted to the difference of the RTTOV BRDF model quality index and surface types mask. The third part of the paper presents the difference of the two collections on TOA simulated reflectance compared to clear-sky SEVIRI observations. The fourth part presents the methodology we used to extend the snow-free land surface BRDF model to snow-covered surface and a dedicated validation exercise with in situ snow spectral albedo measurements. The fifth part gives the conclusion and future developments of this work.

\section{Materials and Methods}

The RTTOV monthly means land BRDF atlas is currently based on the MODIS C5 MCD43C1 product (see https://lpdaac.usgs.gov/dataset_discovery/modis/modis_products_table/mcd43c1). The MCD43C1 is a Level 3 BRDF kernel-driven product from the operational MODIS land surface products [10]. It combines Terra and Aqua satellites over a 16-day period of acquisition and is provided globally at spatial resolution of $0.05^{\circ}$. This product was derived from the original $1-\mathrm{km}$ spatial 
resolution of MODIS data and was developed for the global modeling community [11]. The MODIS BRDF is modeled by using the semi empirical linear model of Ross-Li [12] that is given by:

$$
R\left(\theta_{\text {sat }}, \theta_{\text {sol }}, \Delta \varphi, \lambda\right)=f_{\text {iso }}(\lambda)+f_{\text {vol }}(\lambda) K_{\text {vol }}\left(\theta_{\text {sat }}, \theta_{\text {sol }}, \Delta \varphi\right)+f_{\text {geo }}(\lambda) K_{\text {geo }}\left(\theta_{\text {sat }}, \theta_{\text {sol }}, \Delta \varphi\right)
$$

where $\theta_{\text {sat }}, \theta_{\text {sol }}$, and $\Delta \varphi$ are the satellite zenith angle, the solar zenith angle, and the azimuth difference between satellite and solar directions, respectively; $\lambda$ is the wavelength. $f_{i s o}$ is due to isotropic scattering, $f_{v o l}$ is due to volumetric scattering as from horizontally homogeneous leaf canopies, and $f_{\text {geo }}$ is due to geometric-optical surface scattering as from scenes containing 3-D objects that cast shadows and are mutually obscured from view at off-nadir angles. The formulation of the BRDF model kernels $K_{v o l}$ and $K_{\text {geo }}$ can be found in Lucht et al. [12].

The MCD43C1 product contains the three retrieved BRDF model parameters $f_{i s o}, f_{\text {vol }}$, and $f_{\text {geo }}$ for each MODIS VIS/NIR channel and three associated pieces of information on quality and inputs (a retrieval quality flag, the percentage of inputs from the original 1-km spatial resolution of MODIS between 0 and $100 \%$, and the percentage of snow coverage between 0 and $100 \%$ ). The MODIS products are globally able to capture the seasonal cycle of snow-free surface albedo with a typical accuracy better than 0.05 but are also found to be less accurate for higher solar zenith angles [13]. The study of Wang and Zender [14] found that the accuracy over snow deteriorates for SZA $>55^{\circ}$, but Schaaf and Strahler [15] contradicted this finding by arguing an inappropriate use of the extensive quality flags and showed that the MODIS product performs quite well out to the recommended limit for product use of $70^{\circ}$ SZA.

We have improved the RTTOV BRDF atlas by using the last collection 6 (C6) of the MODIS MCD43C1 products [16]. The main differences of the two versions are the following. Firstly, the MCD43C1 products are generated daily instead of every 8 days, but still using the 16-day retrieval algorithm. Secondly, all available observations are used at high latitudes in order to improve the number and the quality of the retrieval. Lastly, the current day snow status is used instead of the majority snow/no-snow status from the 16-day period. The generation of the new RTTOV BRDF atlas follows the one that is described in Vidot and Borbás [6] and will be described here. For all original MODIS MCD43C1 data within a month, we extracted the information for a $2 \times 2$ pixel box (from an original pixel resolution at $0.05^{\circ}$ to the final grid at $0.1^{\circ}$ ). The retrieved BRDF model parameters are averaged over the 4 pixels multiplied by the number of days within each month. As compared with $\mathrm{C} 5$, we then have many more pixels to average.

\section{Results}

\subsection{Mask and Quality Index Improvement}

Additionally, to the monthly means BRDF atlas, a mask is provided for each of the BRDF datum providing information on the surface type (water, snow-free land with three levels of retrieval quality, snow with two levels of retrieval quality, and no data). On the panel of Figure 1 are shown global maps of the BRDF mask between the one derived from C5 and the one derived from C6 in July 2007 (Figure 1a,b) and in December 2007 (Figure 1c,d). The mask is based on the quality flag of the MODIS MCD43C1 product using an iterative process and is fully described in Vidot and Borbás [6]. There are seven flags in the mask which are defined as:

- Water surfaces: Based on the land/water mask from the UWIREMIS atlas.

- Good quality retrieval: No snow, best, and good MCD43C1 quality for $80 \%$ inputs or more.

- Medium quality retrieval: No snow, medium MCD43C1 quality for $80 \%$ inputs or more.

- Low quality retrieval: Remaining no snow pixels.

- Snow surfaces: Full snow.

- Bad quality retrieval: Remaining pixels containing snow.

- No data: Remaining pixel from land/water mask with no BRDF retrieval. 


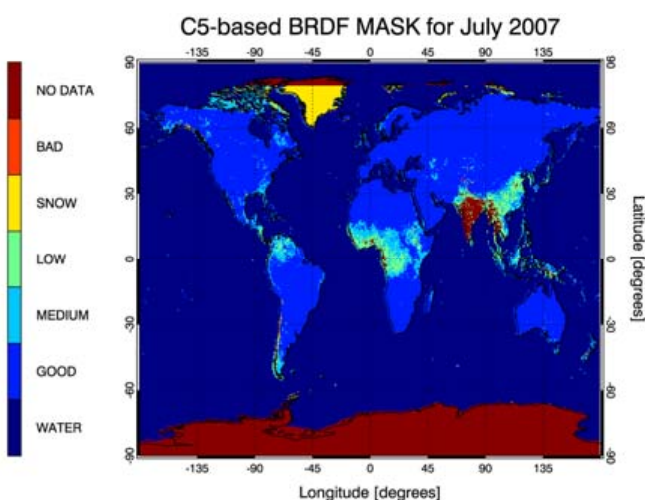

(a)

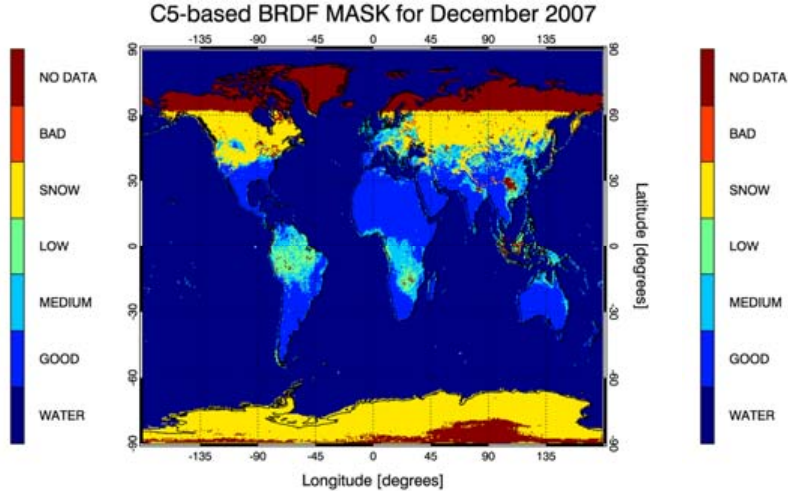

(c)

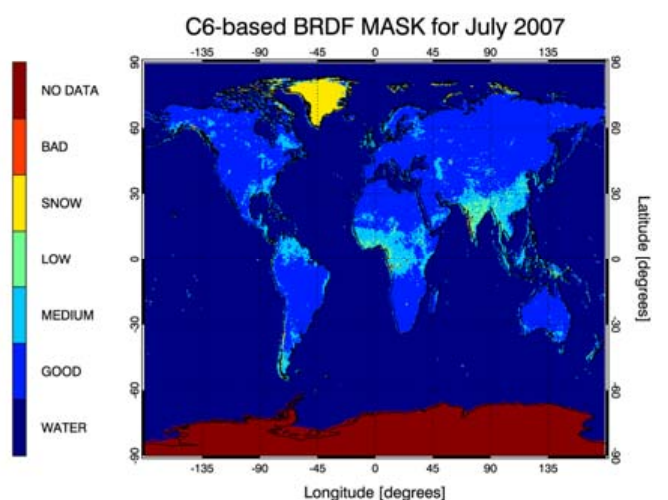

(b)

C6-based BRDF MASK for December 2007

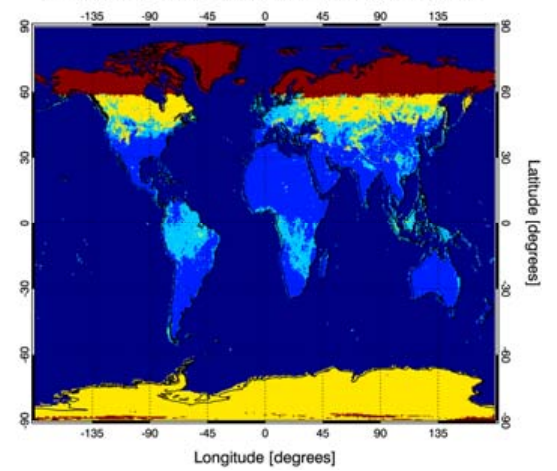

(d)

Figure 1. RTTOV Bidirectional Reflectance Distribution Function (BRDF) mask and quality index: (a) For July 2007 based on C5; (b) For July 2007 based on C6; (c) For December 2007 based on C5; (d) For December 2007 based on C6.

For the two months represented in Figure 1, the number of "Bad" retrieval quality and "No data" flags (in orange and red) over India (Figure 1a), China, or Indonesia (Figure 1c) is greatly reduced with C6 as well as the number of "Low" retrieval quality flags (in green over the Tropics). The "Bad" and "Low" retrieval quality flags from C5 are mainly due to the low retrieval performance of the MODIS product in areas with strong aerosol and residual cloud contamination. By using the higher frequency of $\mathrm{C} 6$ products, which are provided on a daily basis instead of an 8-day basis, we obtained more cases with higher MCD43C1 quality leading to a better RTTOV BRDF quality index. The effect of using all available observations at high latitudes in C6 compared to C 5 can be also seen over Greenland where the number of snow pixels has increased (Figure 1a,b). However, as we wanted to have as much as possible snow-free surface information in the BRDF model, we put more weight on snow-free retrieval. The consequence of using the daily basis of $\mathrm{C} 6$ is that we have more probability to get snow-free information within each month. This leads to a reduction of RTTOV BRDF snow flag as seen over high northern latitudes (Figure 1c,d).

Overall, we compared each flag for three latitudinal areas in both hemispheres for the year 2007. For that, we separated latitudes in polar (latitudes above or below $60^{\circ}$ ), mid-latitudes (latitudes between $23.5^{\circ}$ and $60^{\circ}$ or between $-23.5^{\circ}$ and $-60^{\circ}$ ), and tropical (latitudes between $\pm 23.5^{\circ}$ ). Figure 2 shows the temporal evolution of the percentage of each flag compared to the total land pixels for the three areas (rows) and for the two hemispheres (columns). For almost all areas (except Polar Southern Hemisphere (SH)), the percentage of "Low" retrieval quality flags has decreased (in green dashed lines for C5 and green full lines for (6) and the percentage of "Medium" retrieval quality flags has increased (in cyan dashed lines for C5 and cyan full lines for C6). 

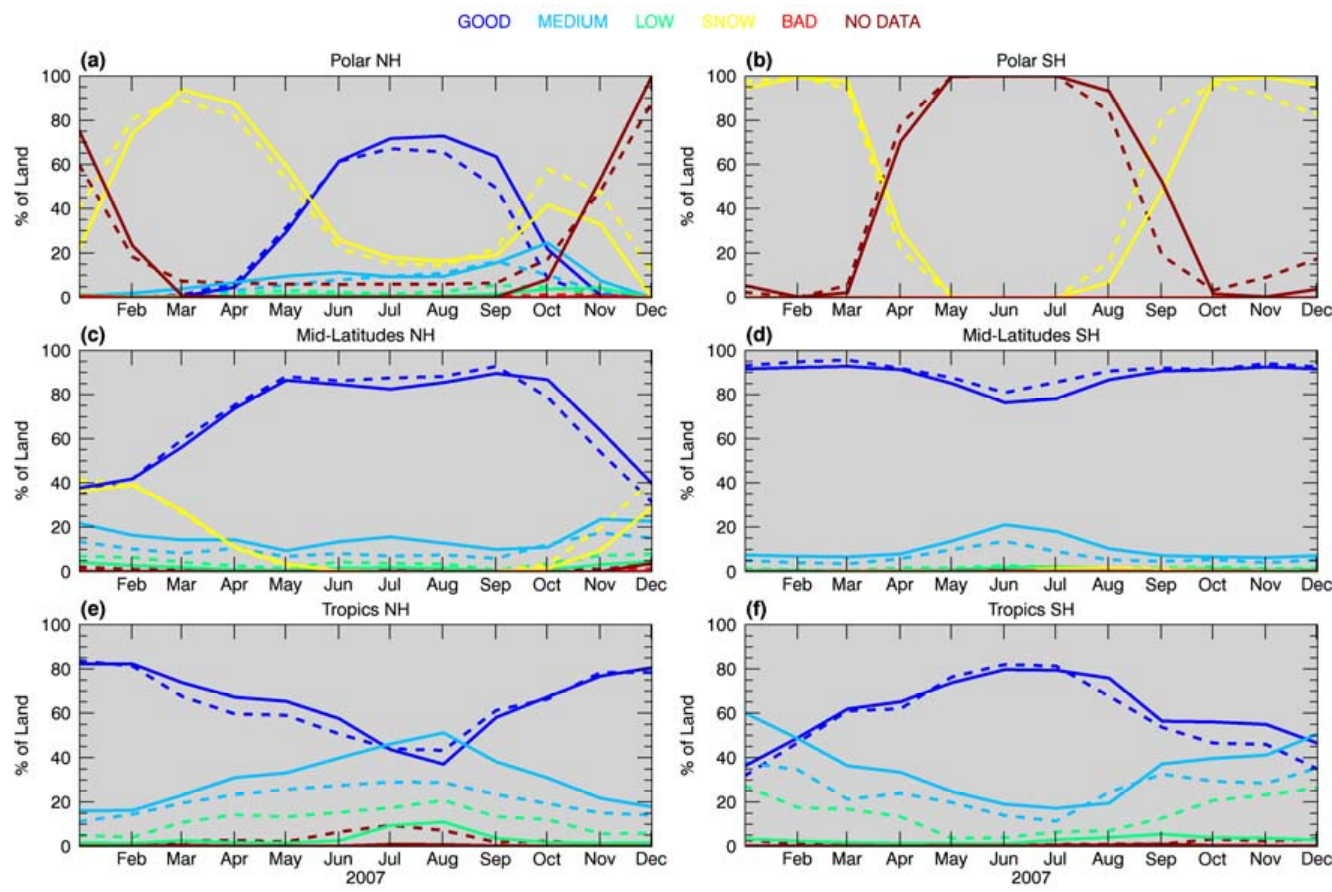

Figure 2. Temporal evolution of the percentage of each flag in 2007. The dashed lines represent C5 and the full lines the C6: (a) For Polar regions of the Northern Hemisphere; (b) For Polar regions of the Southern Hemisphere; (c) For Mid-Latitudes of the Northern Hemisphere; (d) For Mid-Latitudes of the Southern Hemisphere; (e) For the Tropics of the Northern Hemisphere; (f) For the Tropics of the Southern Hemisphere. Colors are similar to those of Figure 1.

For Tropical regions, the percentage of "No data" has been reduced to almost zero (represented in full red lines in Figure 2e,f). The percentages of "Good" retrieval quality flags or "Snow" flags have changed slightly between $\mathrm{C} 5$ and $\mathrm{C} 6$, but we can conclude that the percentage of "Good" quality retrieval from C6 (full blue lines) is around 70\% over Polar Northern Hemisphere (NH) during summer time (Figure 2a). It is between $40 \%$ and $85 \%$ in Mid-Latitudes NH (Figure 2c) and Tropics (Figure 2e,f) depends on the season and between $80 \%$ and $90 \%$ in Mid-Latitudes SH (Figure 2d).

\subsection{Comparison for SEVIRI TOA Reflectances}

The evaluation of the monthly BRDF atlas has been realized by comparing SEVIRI clear-sky top of atmosphere (TOA) observations to simulations on 3 July 2017 in the three visible and near infrared SEVIRI channels (channel 1 centered at $0.6 \mu \mathrm{m}$, channel 2 centered at $0.8 \mu \mathrm{m}$, and channel 3 centered at $1.6 \mu \mathrm{m}$ ). To simulate clear-sky TOA reflectances, we used the atmospheric profiles (pressure, temperature, and water vapor) and surface pressure from the Global UK MetOffice NWP model [17] and RTTOV version 12. In order to check the ability of representing the BRDF for different geometrical situations, we compared the observed and simulated TOA reflectances every hour from 8:00 UTC to 18:00 UTC. This temporal window was chosen to ensure observations during daytime with various solar illuminations including large zenith angles. It is worth mentioning here that aerosols were not included in the simulations. On the panel of Figure 3 is shown the clear-sky SEVIRI TOA reflectance at 12:00 UTC (left column) and simulated TOA reflectance with C5 (middle column) and with C6 (left column) for the three channels (channels 1 to 3 from top to bottom rows, respectively). 


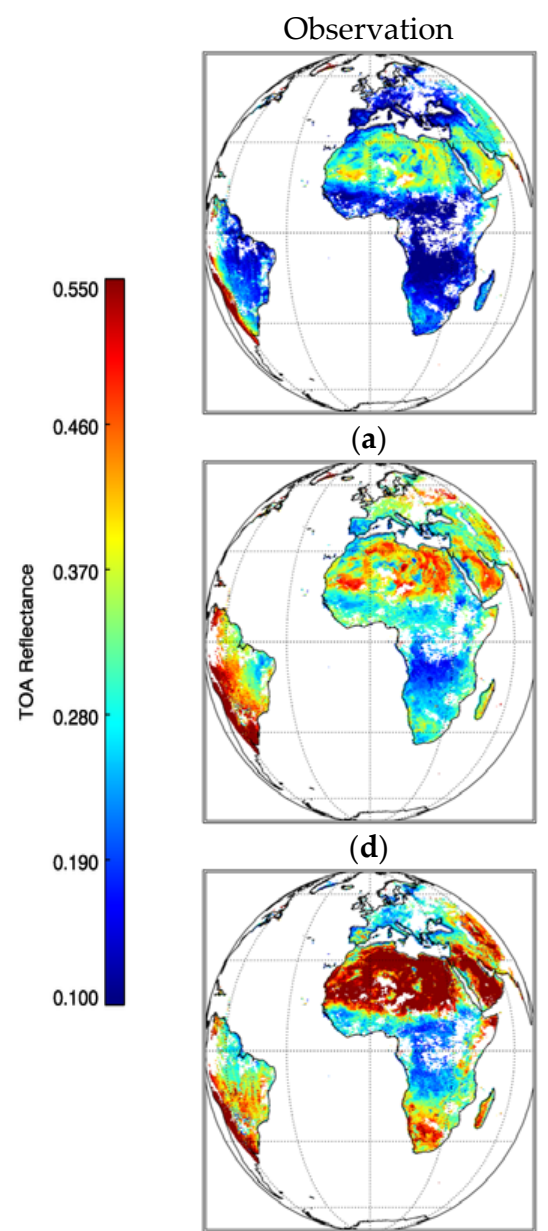

(g)

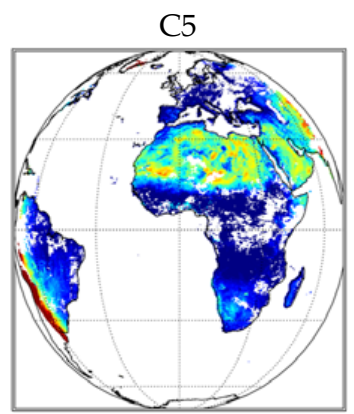

(b)

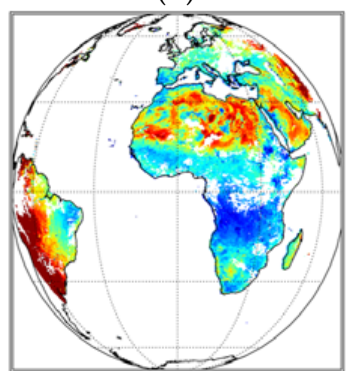

(e)

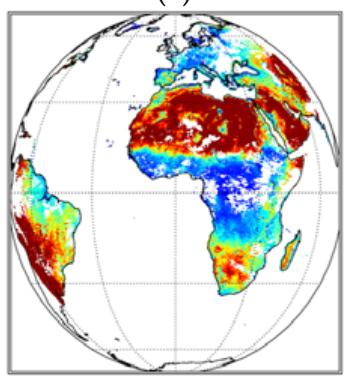

(h)

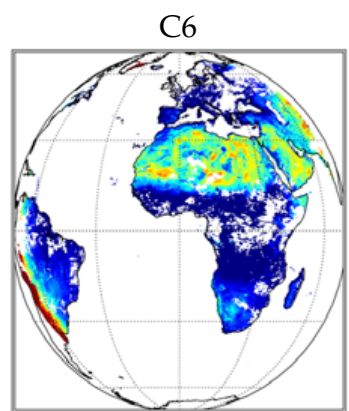

(c)

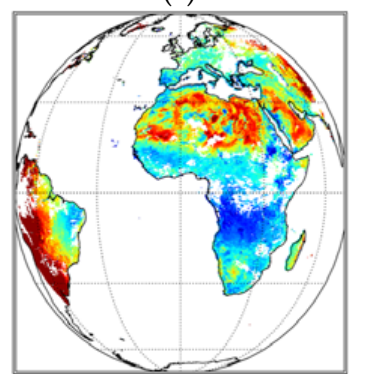

(f)

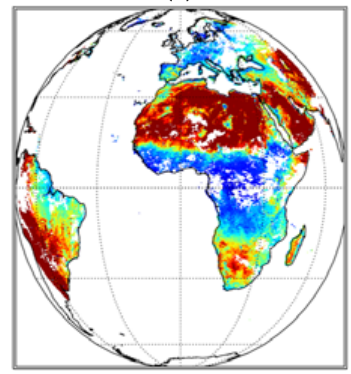

(i)

Figure 3. Observed and simulated top of atmosphere (TOA) clear-sky reflectance in three Spinning Enhanced Visible and InfraRed Imagers (SEVIRI) solar channels: (a-c) Observed, simulated with C5, and simulated with $\mathrm{C} 6$ for channel 1 at 0.6 microns, respectively; (d-f) Observed, simulated with C5, and simulated with C6 for channel 2 at 0.8 microns, respectively; (g-i) Observed, simulated with C5, and simulated with $\mathrm{C} 6$ for channel 2 at 1.6 microns.

The panel of Figure 3 shows that the BRDF model of RTTOV is well suited to represent the spatial distribution of TOA reflectances. However, it can be also noticed that the TOA reflectances are often overestimated at the edge of the disk. The panel of Figure 4 shows the angular effect in the performance of the RTTOV BRDF model to simulate SEVIRI as well as the difference between the two collections. The effect of the viewing zenith angle (VZA), the solar zenith angle (SZA), and the scattering angle (SCA) is shown on Figure $4 a-i$, respectively. For each angle, the top panel of Figure 4 represents the mean bias of the TOA reflectance observed minus the simulated in function of the angle whereas the bottom panel of Figure 4 represents the standard deviation of the differences between observations and simulations in function of the angle. For VZA and SZA, the data were combined in $5^{\circ}$ bins between 0 and $90^{\circ}$ whereas for SCA the data were combined in $10^{\circ}$ bins between 0 and $180^{\circ}$. The colors refer to the channels whereas the line styles refer to the MODIS collections (plus for C5 and dots for C6). For SEVIRI, there are no observations over land for VZA between 0 and $5^{\circ}$, and the scattering angle range were found to be between $70^{\circ}$ and $170^{\circ}$. The results show that the mean bias is less than $0.03-0.05$ and the standard deviation is less than 0.05 for most of situations. However, the results show also that the mean bias strongly decreases at higher VZA (above $70^{\circ}$ ) leading to an overestimation from RTTOV (Figure 4a). The effect is more important in the near infrared (in green) than in the visible (in blue). The standard deviation also greatly increases for VZA above $70^{\circ}$ (Figure $4 \mathrm{~d}$ ) and can reach 
0.5 for the channel 3. The standard deviation also increases for SZA between 60 and $70^{\circ}$ and for low or high SCA. Additionally, we can see that there is a slight underestimation of RTTOV at low VZA that seems to be at its worst with C6 (Figure 4a). This effect can be also seen in Figure 3h,i when compared to Figure $3 g$ for Central Africa. The values of remaining biases and standard deviations might be explained by different factors. The first one comes from the fact that we did not include aerosols in our simulations. Aerosols may have a strong impact on the simulations depending on the aerosol loading. The positive bias at medium angle may also be explained by the Lambertian approximation that is used in the MODIS retrieval and has been shown to underestimate the retrieved surface reflectance [18]. Others errors coming from atmospheric correction in MODIS retrieval or errors from RTTOV simulations are potential explanations. The overestimation of RTTOV as compared with observations at high VZA might be explained by the inaccuracy of the Ross-Li model [12] at these high angles or the inadequacy of such angles in the MODIS retrieval process. Finally, we can conclude that there are no strong differences between $\mathrm{C} 5$ and $\mathrm{C} 6$, and both collections provide accurate BRDF description for VZA below $70^{\circ}$ with TOA reflectance bias below $3 \%$. In comparison, the SEVIRI operational calibration was found to be stable during the years 2004 to 2009 , with an offset of $-8 \%$ at $0.6 \mu \mathrm{m},-6 \%$ at $0.8 \mu \mathrm{m}$, and $+3.5 \%$ at $1.6 \mu \mathrm{m}$ compared to MODIS [19].

(a) Obs-Sim Mean Bias

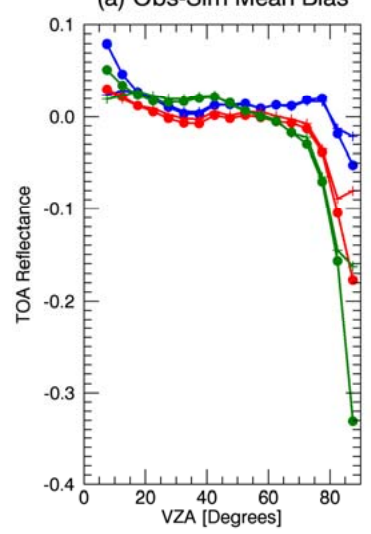

(d) Obs-Sim Stdev

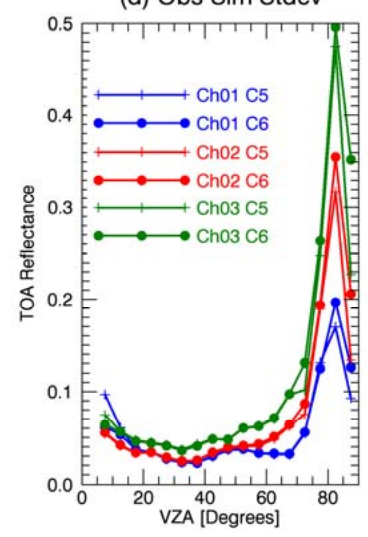

(b) Obs-Sim Mean Bias

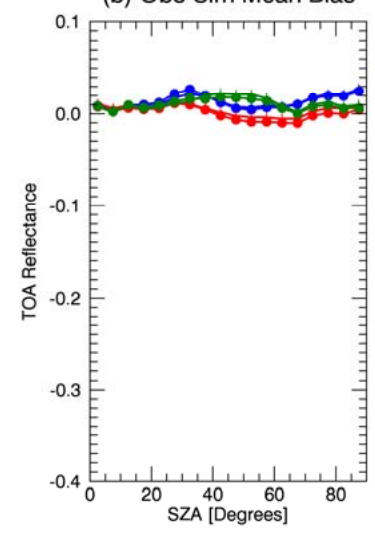

(e) Obs-Sim Stdev

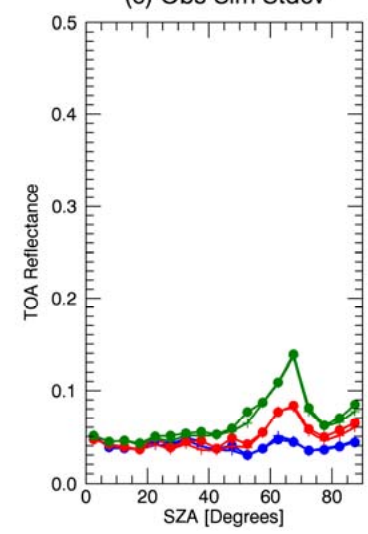

(c) Obs-Sim Mean Bias
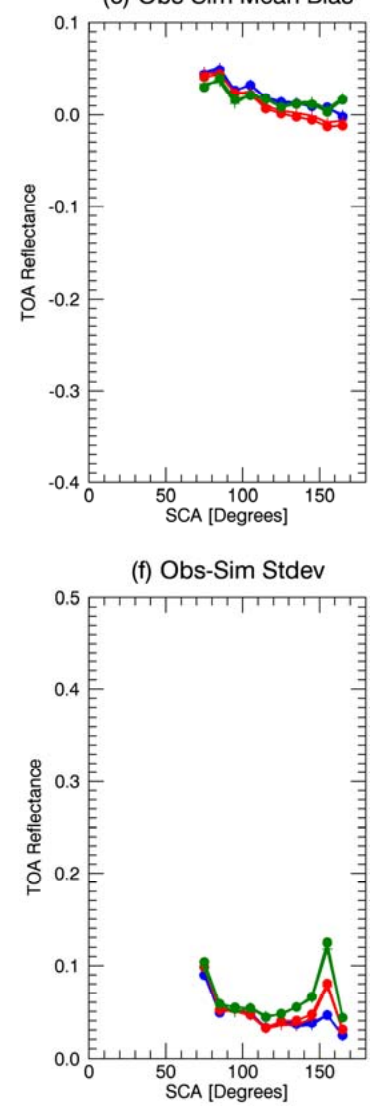

Figure 4. (a) Observations minus simulations mean bias of the TOA reflectances as a function of the viewing zenith angle (VZA); (b) Same as (a) as a function of solar zenith angle (SZA); (c) Same as (a) as a function of the scattering angle (SCA); (d-f) Standard deviation of the observations minus simulations TOA reflectances as a function of VZA, SZA, and SCA, respectively. The different colored lines and styles refer to the Moderate Resolution Imaging Spectroradiometer (MODIS) collection and SEVIRI channels as explained in the legend. 


\subsection{Comparison with In Situ Snow Spectral Albedo}

Since RTTOV version 11.2, we extended the BRDF model to snow surfaces following the methodology developed for the land surfaces. For that we applied the principal component analysis on snow spectral albedo (defined as directional-hemispherical reflectance for direct beam at a certain solar zenith angle or also named black-sky albedo). To cover the whole possible range of snow reflectance variations, we simulated snow spectral albedo with different snow optical properties and for different solar zenith angles. The snow spectral albedo is influenced by many factors, such as the refractive index of ice [20], the snow microphysical properties, and the presence of light absorbing impurities within the snow pack [21]. To simulate the snow spectral albedo, we used the DIScrete Ordinate Radiative Transfer (DISORT) model [22]. The DISORT model was applied to a plane-parallel multi-layer snowpack where the single scattering properties of snow were computed with the Mie theory. The spherical assumption is acceptable to model only the bi-hemispherical reflectance of snow [23]. We refer to the work of Carmagnola et al. [24] (parts 2.2.1) for the full description of the simulation of the snow spectral albedo. In our simulations we used the snow Specific Surface Area (SSA) to characterize the optically relevant size of the snow grain. The snow SSA is impacted by the snow metamorphism. A high value of SSA is often related to fresh snow whereas a small value can be related to melt-frozen snow. Additionally, the presence of impurities also impacts the snow spectral albedo. The DISORT simulations have been successfully compared with in situ measurements [24]. The panel of Figure 5 shows different simulated snow spectral albedos between 0.4 and $2.5 \mu \mathrm{m}$ for $\mathrm{SZA}=0^{\circ}$ and $\mathrm{SZA}=60^{\circ}$ (Figure 5a,b, respectively). The different green to purple lines show the effect of SSA on the simulated snow spectral albedo, whereas the orange to red lines show the effect of Black Carbon Content (BCC). All simulated spectra show typical features of snow albedo (high value in the VIS that decrease with wavelength with peaks near 1.1, 1.3, 1.85, and 2.25 which correspond to the minima of the absorption coefficient of pure snow [21]).

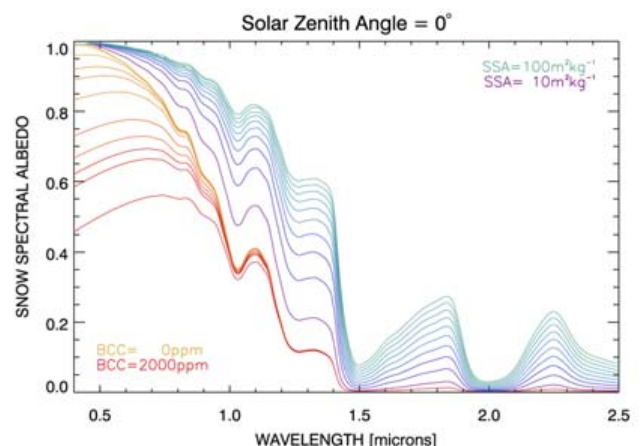

(a)

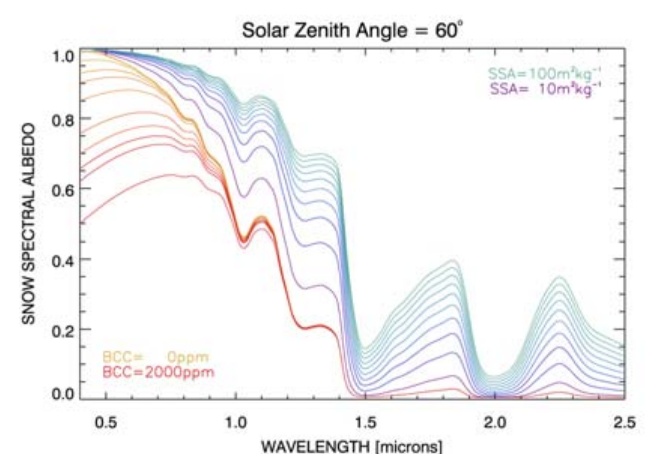

(b)

Figure 5. Snow spectral albedo versus wavelength simulated for different values of the snow Specific Surface Area (SSA) (green to purple lines) and for different black carbon content (orange to red lines) for $\mathrm{SZA}=0^{\circ}(\mathbf{a})$ and for $\mathrm{SZA}=60^{\circ}(\mathbf{b})$.

The Figure 5a,b shows also that when the snow microstructure is fine, i.e., for high SSA values (in green), the albedo is high, and when the snow microstructure is coarser, i.e., when the SSA decreases, the snow spectral albedo decreases in the near infrared part. In the visible part, when the content of black carbon increases, the snow spectral albedo decreases. In addition, higher SZA lead to higher albedo. The full database of snow spectral albedos was simulated using SZA between 0 and $85^{\circ}$ by steps of $5^{\circ}$, the snow SSA between 5 and $100 \mathrm{~m}^{2} \cdot \mathrm{kg}^{-1}$ by steps of $5 \mathrm{~m}^{2} \cdot \mathrm{kg}^{-1}$, and BCC of $0.1,0.5,1,5,10$, to 50 (by steps of 10), 100 to 1000 (by step of 100), 1000, and 2000 ppm. This database was used in the same way as for land surface to reconstruct hyperspectral BRDF spectra by constraining/fitting the satellite-derived BRDF retrievals at specific channels with the principal components of this representative set of snow spectral albedo. 
To validate the snow BRDF RTTOV model, we used in situ snow spectral albedo measurements made at Summit Camp in Greenland $\left(72^{\circ} 36^{\prime} \mathrm{N}, 38^{\circ} 25^{\prime} \mathrm{W}, 3210 \mathrm{~m}\right.$ a.s.l.) during two months in 2011 [22]. However, there may be a directional dependence of snow BRDF that is not properly evaluated by the albedo comparison as the snow reflectance is not fully isotropic. A complete validation would require snow BRDF measurements instead of albedos. The instrument is the ASD FieldSpec Pro spectroradiometer with a spectral range of 0.35 to $2.2 \mu \mathrm{m}$ and a spectral resolution ranging from $3 \mathrm{~nm}$ in the UV to $12 \mathrm{~nm}$ in the NIR. The measurements accuracy is below $0.3 \%$ of the albedo over the full spectrum except between 1.8 and $1.9 \mu \mathrm{m}$ due to low signal/noise ratio. The measurements were all acquired around 11:00 LT, checked for quality and cloud screening, and corrected from measurements artifacts that are fully described in Carmagnola et al. [24]. We used 19 spectra (8 in May 2011 and 11 in June 2011) with SZA ranging between $49.1^{\circ}$ and $58.8^{\circ}$ (see Table 1). Figure 6 shows the measured spectra used in this study (in blue for May and in red for June). The variability seen in the measured spectra can be mostly explained by the change in snow properties since the SZA did not change much during the measurements. The interpretation of this variability is beyond the scope of this study and is described in Carmagnola et al. [24].

Table 1. Date and solar zenith angles of the in situ measurements.

\begin{tabular}{cc}
\hline Date & SZA \\
\hline 16 May 2011 & $53.2^{\circ}$ \\
17 May 2011 & $58.8^{\circ}$ \\
19 May 2011 & $52.6^{\circ}$ \\
22 May 2011 & $52.1^{\circ}$ \\
25 May 2011 & $51.5^{\circ}$ \\
28 May 2011 & $51.0^{\circ}$ \\
30 May 2011 & $50.7^{\circ}$ \\
31 May 2011 & $50.6^{\circ}$ \\
1 June 2011 & $50.4^{\circ}$ \\
2 June 2011 & $50.3^{\circ}$ \\
3 June 2011 & $50.2^{\circ}$ \\
7 June 2011 & $50.6^{\circ}$ \\
10 June 2011 & $49.5^{\circ}$ \\
11 June 2011 & $49.4^{\circ}$ \\
15 June 2011 & $50.5^{\circ}$ \\
20 June 2011 & $50.4^{\circ}$ \\
22 June 2011 & $54.5^{\circ}$ \\
24 June 2011 & $49.8^{\circ}$ \\
25 June 2011 & $49.1^{\circ}$ \\
\hline
\end{tabular}

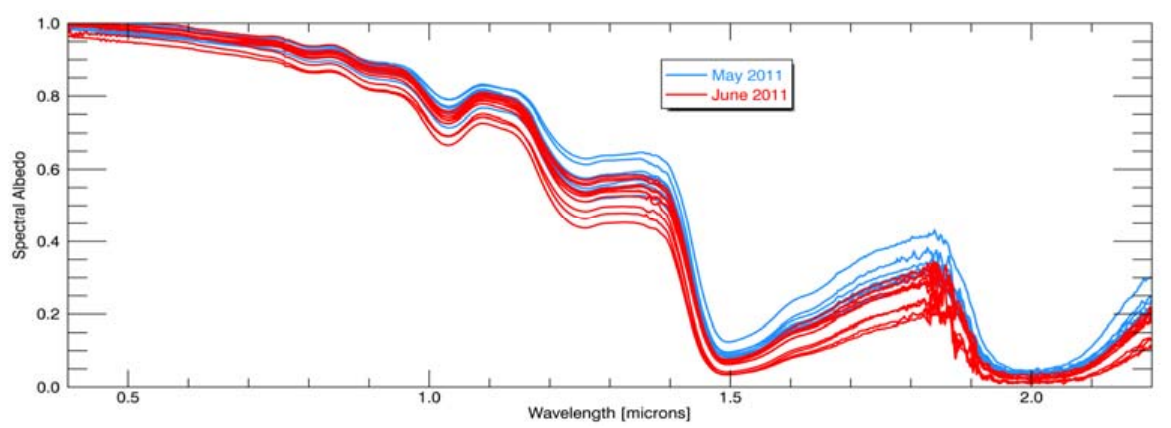

Figure 6. Snow spectral albedo measurement by the ASD spectroradiometer in May (blue lines) and in June (red lines).

Since the RTTOV BRDF model is provided on a monthly basis, we calculated the mean snow spectral albedo for the two months of the in situ measurements. The snow spectral albedo is calculated 
using Equation (4) of Vidot and Borbás [6] (i.e., as black-sky albedo). It is worth mentioning that in situ snow spectral albedo contains both black-sky albedo and white-sky albedo (bihemispherical reflectance under isotropic radiation) weighted by the proportion of diffuse irradiance [13], which is the function of the aerosol optical depth under clear-sky conditions. In this comparison, we considered that the diffuse component is negligible as compared to the direct component. This is supported by the fact that typical aerosol optical depth is low at Summit $(0.05$ at $500 \mathrm{~nm})$ [25] and that the snow spectral albedo is similar to the black-sky albedo for moderate SZA (see Figure 1 of Liu et al. [13]). The top panel of Figure 7a displays the mean snow spectral albedo from in situ measurements made in May 2011 (in blue), and the blue shaded area between black lines represents the standard deviation. The red curve represents the snow spectral albedo calculated from the RTTOV BRDF model with C5 whereas the green line represents the snow spectral albedo calculated from the RTTOV BRDF model with C6. The bottom panel of Figure 7a represents the difference between the mean spectral albedo from measurements and the monthly mean calculated snow spectral albedo. The Figure $7 \mathrm{~b}$ represents the same results for June 2011. MODIS C5 and C6 simulate both the spectral dependence of snow but underestimate the albedo compared to in situ measurements. However, the C6-based BRDF model clearly improves the simulations everywhere in the spectrum as compared those of with C5. This result has been also shown by Wright et al. [25] for MODIS channels. Almost no biases are found in the visible part of the spectrum with C6, whereas it was 0.05 for May and 0.1 for June with C5. In the near infrared part, an underestimation of the albedo still remains in May of a maximum of 0.05 .

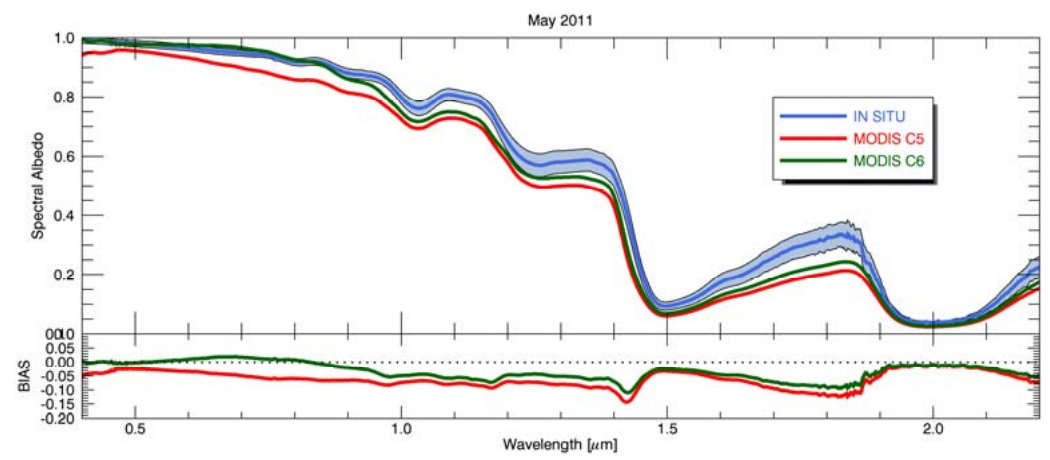

(a)

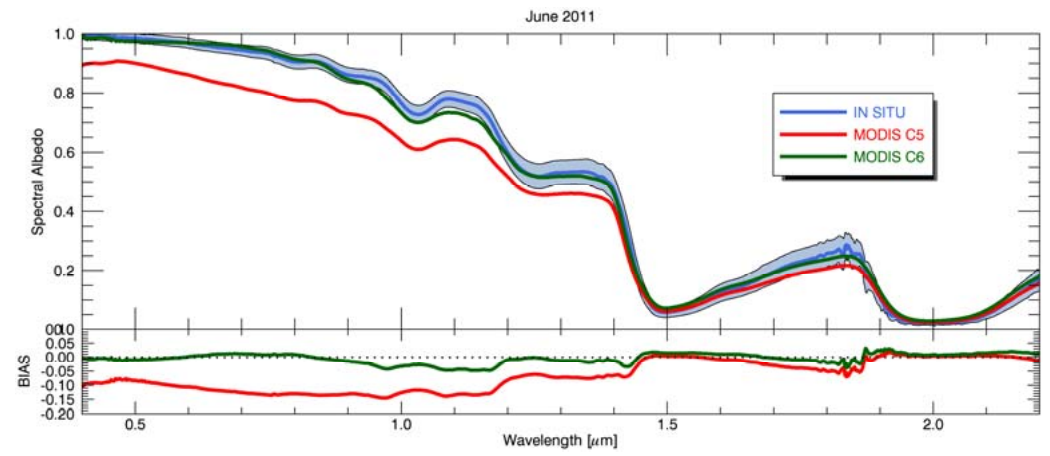

(b)

Figure 7. (a) Snow spectral albedo (top) and bias (bottom) between then mean spectral albedo measured by the ASD spectroradiometer in May (blue line), and black lines represents the +/ - standard deviation. The spectral albedo from C5 and C6 are represented in red and green, respectively; (b) Same as (a) for June.

\section{Conclusions}

An improvement of the land and snow surface BRDF model for RTTOV has been studied here. It is based on the last collection C6 of the MODIS MCD43C1 product. The evaluation of this new BRDF model has been proposed for snow-free land surfaces and snow-covered surfaces with two types of 
observations. For snow-free land surfaces, we compared SEVIRI TOA reflectances at 0.6, 0.8, and $1.6 \mu \mathrm{m}$ with simulations made using RTTOV version 12 and the Global UK Met-Office NWP model. We complemented our evaluation by using the temporal frequency of observations every hour during daytime to estimate the performance of the BRDF model as a function of the viewing and solar zenith angles as well as the scattering angles. For snow-covered surfaces, we used in situ snow spectral albedo measurements in the VIS/NIR over the Summit Camp in Greenland during two months to check the spectral consistency between the simulations and the observations.

Since the C6 MODIS product is provided on a daily basis (as compared to the 8-days of C5), we firstly showed that the quality index of the RTTOV land and snow surface BRDF model is improved leading to a strong reduction of the lower BRDF retrieval quality index. We showed secondly that both C5 and C6 performed almost equally in simulating SEVIRI clear-sky observations. We concluded that the land surface BRDF model is accurate when VZA and SZA are below $70^{\circ}$ with an estimated error below 3\% to 5\% in TOA reflectance in the three VIS/NIR channels. Thirdly, we showed that the MODIS C6 product improved the simulations for snow surfaces, especially in the visible part of the spectrum where for the two months studied here almost no bias was found. In the near infrared part of the spectrum, an underestimation of the simulated snow spectral albedo was found with C6 but this underestimation was lower than that of the simulations with C5.

In the future, we plan to extend the database to other years since only the year 2007 is implemented in RTTOV. The MODIS C6 product is now provided for 2000 and 2017. We also plan in the framework of the SAF-NWP project to extend the capability of RTTOV into the ultraviolet. This objective is motivated by the use of the high spectral resolution of the RTTOV BRDF model to simulate UV/VIS/NIR hyperspectral spectrometers that will fly onboard the Sentinel-5 and the Meteosat Third Generation (MTG) satellites.

Acknowledgments: This work was funded by the EUMETSAT NWP-SAF project. The MCD43C1 product was retrieved from the online data pool, courtesy of the NASA EOSDIS Land Processes Distributed Active Archive Center (LP DAAC), USGS/Earth Resources Observation and Science (EROS) Center, Sioux Falls, South Dakota. We thank anonymous reviewers for making suggestion to improve the manuscript.

Author Contributions: Jerome Vidot conceived, designed, and performed the experiments; Jerome Vidot and Pascal Brunel analyzed the results; James Hocking, Marie Dumont, and Carlo Carmagnola provided the data for validation; Jerome Vidot wrote the paper.

Conflicts of Interest: The authors declare no conflict of interest.

\section{References}

1. Saunders, R.; Matricardi, M.; Brunel, P. An improved fast radiative transfer model for assimilation of satellite radiance observations. Q. J. R. Meteorol. Soc. 1999, 125, 1407-1425. [CrossRef]

2. Matricardi, M.; Chevallier, F.; Kelly, G.; Thépaut, J.-N. An improved general fast radiative transfer model for the assimilation of radiance observations. Q. J. R. Meteorol. Soc. 2004, 130, 153-173. [CrossRef]

3. Errico, R.M.; Ohring, G.; Weng, F.; Bauer, P.; Ferrier, B.; Mahfouf, J.; Turk, J. Assimilation of Satellite Cloud and Precipitation Observations in Numerical Weather Prediction Models: Introduction to the JAS Special Collection. J. Atmos. Sci. 2007, 64, 3737-3741. [CrossRef]

4. Dee, D.P.; Uppala, S.M.; Simmons, A.J.; Berrisford, P.; Poli, P.; Kobayashi, S.; Andrae, U.; Balmaseda, M.A.; Balsamo, G.; Bauer, P.; et al. The ERA-Interim reanalysis: Configuration and performance of the data assimilation system. Q. J. R. Meteorol. Soc. 2011, 137, 553-597. [CrossRef]

5. Saunders, R.; Hocking, J.; Rundle, D.; Rayer, P.; Matricardi, M.; Geer, A.; Lupu, C.; Brunel, P.; Vidot, J. RTTOV-11 Science and Validation Report. NWP-SAF Report. 2013. Available online: https:/ / www.nwpsaf. eu/site/download/documentation/rtm/docs_rttov11/rttov11_svr.pdf (accessed on 17 November 2017).

6. Vidot, J.; Borbás, É. Land surface VIS/NIR BRDF atlas for RTTOV-11: Model and validation against SEVIRI land SAF albedo product. Q. J. R. Meteorol. Soc. 2014, 140, 2186-2196. [CrossRef]

7. Seemann, S.W.; Borbas, E.A.; Knuteson, R.O.; Stephenson, G.R.; Huang, H.-L. Development of a Global Infrared Land Surface Emissivity Database for Application to Clear Sky Sounding Retrievals from Multispectral Satellite Radiance Measurements. J. Appl. Meteorol. Climatol. 2008, 47, 108-123. [CrossRef] 
8. $\quad$ Borbas, E.A.; Ruston, B.C. The RTTOV UWiremis IR Land Surface Emissivity Module; NWP-SAF Report No NWPSAF-MO-VS-042; EUMETSAT: Darmstadt, Germany, 2010; p. 24.

9. Zoogman, P.; Liu, X.; Chance, K.; Sun, Q.; Schaaf, C.B.; Mahr, T.; Wagner, T. A climatology of visible surface reflectance spectra. J. Quant. Spectrosc. Radiat. Transf. 2016, 80, 39-46. [CrossRef]

10. Schaaf, C.B.; Gao, F.; Strahler, A.H.; Lucht, W.; Li, X.; Tsang, T.; Strugnell, N.C.; Zhang, X.; Jin, Y.; Muller, J.-P.; et al. First operational BRDF, albedo nadir reflectance products from MODIS. Remote Sens. Environ. 2002, 83, 135-148. [CrossRef]

11. Gao, F.; Schaaf, C.B.; Strahler, A.H.; Roesch, A.; Lucht, W.; Dickinson, R. MODIS bidirectional reflectance distribution function and albedo Climate Modeling Grid products and the variability of albedo for major global vegetation types. J. Geophys. Res. 2005, 110. [CrossRef]

12. Lucht, W.; Schaaf, C.B.; Strahler, A.H. An Algorithm for the retrieval of albedo from space using semiempirical BRDF models. IEEE Trans. Geosci. Remote Sens. 2000, 38, 977-998. [CrossRef]

13. Liu, J.; Schaaf, C.B.; Strahler, A.H.; Jiao, Z.; Shuai, Y.; Zhang, Q.; Roman, M.; Augustine, J.A.; Dutton, E.G. Validation of Moderate Resolution Imaging Spectroradiometer (MODIS) albedo retrieval algorithm: Dependence of albedo on solar zenith angle. J. Geophys. Res. 2009, 114. [CrossRef]

14. Wang, Z.; Zender, C.S. MODIS snow albedo bias at high solar zenith angles relative to theory and to in situ observations in Greenland. Remote Sens. Environ. 2010, 114, 563-575. [CrossRef]

15. Schaaf, C.B.; Strahler, A.H. Commentary on Wang and Zender-MODIS snow albedo bias at high solar zenith angles relative to theory and to in situ observations in Greenland. Remote Sens. Environ. 2011, 115, 1296-1300. [CrossRef]

16. Schaaf, C.B.; Wang, Z. MCD43C1 MODIS Terra + Aqua BRDF Albedo Model Parameters Daily L3 Global 0.05Deg CMG V006; NASA EOSDIS Land Processes DAAC. 2015. Available online: https:/ /e4ftl01.cr.usgs. gov/MOTA/ (accessed on 17 November 2017).

17. Walters, D.; Boutle, I.; Brooks, M.; Melvin, T.; Stratton, R.; Vosper, S.; Wells, H.; Williams, K.; Wood, N.; Allen, T.; et al. The Met Office Unified Model Global Atmosphere 6.0/6.1 and JULES Global Land 6.0/6.1 configurations. Geosci. Model Dev. 2017, 10, 1487-1520. [CrossRef]

18. Wang, Y.; Lyapustin, A.I.; Privette, J.L.; Cook, R.B.; SanthanaVannan, S.K.; Vermote, E.F.; Schaaf, C.L. Assessment of biases in MODIS surface reflectance due to Lambertian approximation. Remote Sens. Environ. 2010, 114, 2791-2801. [CrossRef]

19. Meirink, J.F.; Roebeling, R.A.; Stammes, P. Inter-calibration of polar imager solar channels using SEVIRI. Atmos. Meas. Tech. 2013, 6, 2495-2508. [CrossRef]

20. Warren, S.G.; Wiscombe, W.J. A Model for the Spectral Albedo of Snow. II: Snow Containing Atmospheric Aerosols. J. Atmos. Sci. 1980, 37, 2734-2745. [CrossRef]

21. Wiscombe, W.J.; Warren, S.G. A Model for the Spectral Albedo of Snow. I: Pure Snow. J. Atmos. Sci. 1980, 37, 2712-2733. [CrossRef]

22. Stamnes, K.; Tsay, S.; Wiscombe, W.; Jayaweera, K. Numerically stable algorithm for discrete-ordinate-method radiative transfer in multiple scattering and emitting layered media. Appl. Opt. 1988, 27, 2502-2509. [CrossRef] [PubMed]

23. Grenfell, T.C.; Warren, S.G. Representation of a nonspherical ice particle by a collection of independent spheres for scattering and absorption of radiation. J. Geophys. Res. 1999, 104, 31697-31709. [CrossRef]

24. Carmagnola, C.M.; Dominé, F.; Dumont, M.; Wright, P.; Strellis, B.; Bergin, M.; Dibb, J.; Picard, G.; Libois, Q.; Arnaud, L.; et al. Snow spectral albedo at Summit, Greenland: Measurements and numerical simulations based on physical and chemical properties of the snowpack. Cryosphere 2013, 7, 1139-1160. [CrossRef]

25. Wright, P.; Bergin, M.; Dibb, J.; Lefer, B.; Domine, F.; Carman, T.; Carmagnola, C.; Dumont, M.; Courville, Z.; Schaaf, C.; et al. Comparing MODIS daily snow albedo to spectral albedo field measurements in Central Greenland. Remote Sens. Environ. 2014, 140, 118-129. [CrossRef]

(C) 2017 by the authors. Licensee MDPI, Basel, Switzerland. This article is an open access article distributed under the terms and conditions of the Creative Commons Attribution (CC BY) license (http:/ / creativecommons.org/licenses/by/4.0/). 